\title{
Süt dişleriyle ilişkili kompound odontoma: Íki olgu
}

\author{
Ebru Küçükyılmaz ${ }^{1}$, Selçuk Savaş ${ }^{1}$, Abdullah Kalaycı ${ }^{2}$, Sibel Yıldııım ${ }^{3}$
}

Selcuk Dental Journal, 2014; 1: 31-35

Başvuru Tarihi: 11 Kasım 2013 Yayına Kabul Tarihi: 03 Şubat 2014

\section{Odontoma associated with primary teeth: Two cases}

Odontomas, which constitue about \%22 of all odontojenic tumors of the jaws, are hamartomatous lesions composed of enamel, dentin, and pulp. Odontomas have been classified as benign odontogenic tumors and are subdivided into complex or compound odontomas morphologically. Compound odontomas commonly occur in the incisor-canine region of the maxilla and they are approximately twice as common as complex odontomas They are usually asymptomatic and found in routine dental radiographic examination. Odontomas are often associated with tooth eruption disturbances, congenital missing of adjacent teeth, resorption, malposition and frequently occur in the permanent dentition, rarely occur in the primary dentition. In this case report; two cases of compound odontoma associated with primary teeth are aimed to present.

\section{KEY WORDS}

\section{Compound odontoma, impacted tooth, primary teeth}

Çenelerin tüm odontojenik tümörlerinin yaklaşı \%22'sini oluşturan odontomalar, mine ve dentini oluşturan ameloblast ve odontoblastların fonksiyonu sonucu ileri derecede farklılaşma gösteren epiteliyal ve mezenşimal hücrelerin birlikte gelişimi ile meydana gelen benign, gelişimsel anomalilerdir (Neville ve ark 2002, Oliveira ve ark 2001). Ektodermal ve mezenkimal kökeni nedeniyle mikst odontojenik tümörler sınıfına giren odontomalar, mikroskobik ve makroskobik özelliklerine göre kompleks ve kompound odontoma olarak ikiye ayrımaktadır. Düzenli şekilli farklı sayıda küçük veya rudimenter diş ve benzeri dokuları içeren normal diş dokusuna yakın özellik gösteren odontomalar kompound odontoma, dental dokuların düzensiz bir kitle oluşturacak şekilde yığılmasıyla oluşan odontomalar ise kompleks odontoma olarak adlandırılmaktadır (Kramar ve ark 1992). Kompound odontoma radyografik olarak, genellikle dar radyolusent bir bölge ile çevrili, normal dişlere anatomik olarak benzer görüntü verirken, kompleks odontoma ise radyografide ince radyolüsent bir alan ile çevrili, diş ile hiçbir anatomik benzerlik taşımayan irregüler şekilli kalsifiye kitleler şeklinde izlenmektedir (Bordini ve ark 2008). Kompound tip odontomaya kompleks tip odontomaya göre daha sı rastlanılmaktadır (\%62), bu tip odontomalar genellikle üst çenede, ön kesici ve kanin diş bölgesinde oluşmaktadırlar. Kompleks odontomalar ise \%70 sıklıkla mandibulada ve premolar-molar bölgesinde görülmektedir (Kramar ve ark 1992, Lee ve Park 2008).

Odontomaların etiyolojisi tam olarak bilinmemekle birlikte travma ve enfeksiyonun odontomaların oluşumu için gerekli şartları yaratabileceği veya genetik faktörlerin etkili olabileceği iddia edilmektedir (Amailuk ve Grubor 2008, Ferrer ve ark 2001). Her iki cinsiyeti eşit olarak etkileyen ve genellikle yaşamın ilk yirmi yılında ortaya çıkan odontomalar, çoğunlukla daimi dişler ile ilişkilidir ve süt dişlerini nadiren tutarlar (Yildirim ve ark 2007, Stajcic 1998).

Genellikle asemptomatik olmaları nedeniyle, odontomaların teşhisi rutin radyografik muayeneler sırasında konmaktadır. Fakat nadiren şişlik, ağrı, iltihap, bölgesel adenopati ve kemikte genişlemeye neden olabilirler. Ayrıca, bu tümörlere bağlı olarak ilgili bölgeye komşu dişlerde germ eksikliği, malpozisyon, diastema, gömük kalma, kist oluşumu, süt dişi retansiyonu, dişlerde çapraşıklık, rezorpsiyon veya yer değiştirme gözlenmektedir (Lee ve ark 2008, Yildirim ve ark 2007, Stajcic 1998, Karacay ve ark 2012, Hisatomi 2002).

\footnotetext{
${ }^{1}$ İzmir Katip Çelebi Üniversitesi Diş Hekimliği Fakültesi Pedodonti Anabilim Dalı, İzmir

2 Selçuk Üniversitesi Diş Hekimliği Fakültesi Ağız, Diş ve Çene Cerrahisi Anabilim Dalı, Konya

${ }^{3}$ Selçuk Üniversitesi Diş Hekimliği Fakültesi Pedodonti Anabilim Dalı, Konya
} 
Bu olgu sunumunda, üst çene ön bölgede süt dişlerinin gömülü olarak kalmasına ve germ eksikliğine neden olan iki farklı kompound odontoma vakasının sunulması amaçlanmıştır.

\section{OLGU 1}

Maksiller sağ süt lateral dişinin sürmemesi şikayeti ile kliniğimize başvuran hastanın $(3,5 ;$; $)$ ebeveyninden alınan anamnez sonucunda herhangi bir sistemik rahatsızlığının bulunmadığı öğrenildi. Yapılan ağız içi muayenesinde sağ maksiller süt lateral diş haricindeki tüm süt dişlerinin ağızda ve normal pozisyonlarında oldukları, ancak eksik olan diş bölgesinde palatinale doğru yayllım gösteren bir şişliğin bulunduğu görüldü (Resim 1).

Ağız-yüz bölgesi ile ilgili herhangi bir travma hikayesinin bulunmadığı öğrenilen hastanın radyolojik muayenesinde; ilgili bölgede radyolusent bir follikül içerisinde yerleşmiş çoklu radyoopak kitlelerin bulunduğu, maksiller sağ süt lateral dişin konjenital olarak eksik olduğu tespit edildi (Resim 2). Odontoma ön tanısı ile hasta Ağız, Diş, Çene Hastalıkları ve Cerrahisi Anabilim Dalı'na yönlendirildi, kitle pedodontist eşliğinde ve lokal anestezi altında çıkarıldı ve flep primer olarak suture edildi. Histopatolojik inceleme neticesinde teşhisin, ön tanımızı destekler nitelikte kompound odontoma olduğu öğrenildi. Postoperatif yara iyileşmesi memnun edici nitelikte olup herhangi bir komplikasyon gözlemlenmedi.

Hastanın 3 yıl süren uzun dönem takibi sonucunda, sağ üst daimi lateral dişin tamamen sürerek dental arktaki yerini aldığı gözlendi (Resim 3, 4).

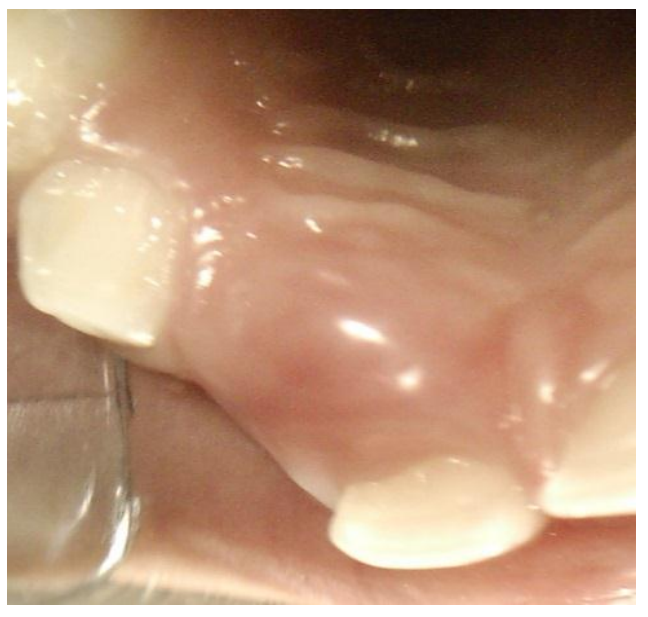

Resim 1.

Eksik olan diş bölgesinde palatinale doğru yayılım gösteren şişlik

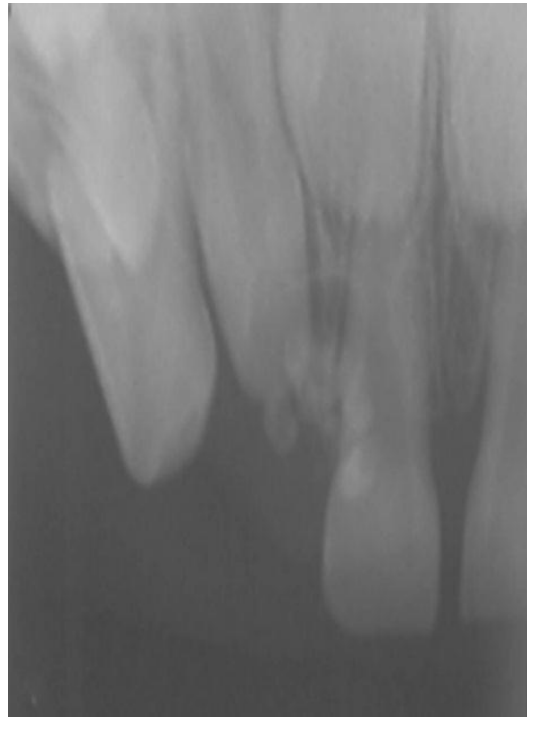

Resim 2.

Konjenital lateral eksikliği ve çoklu radyoopak kitlenin görünümü

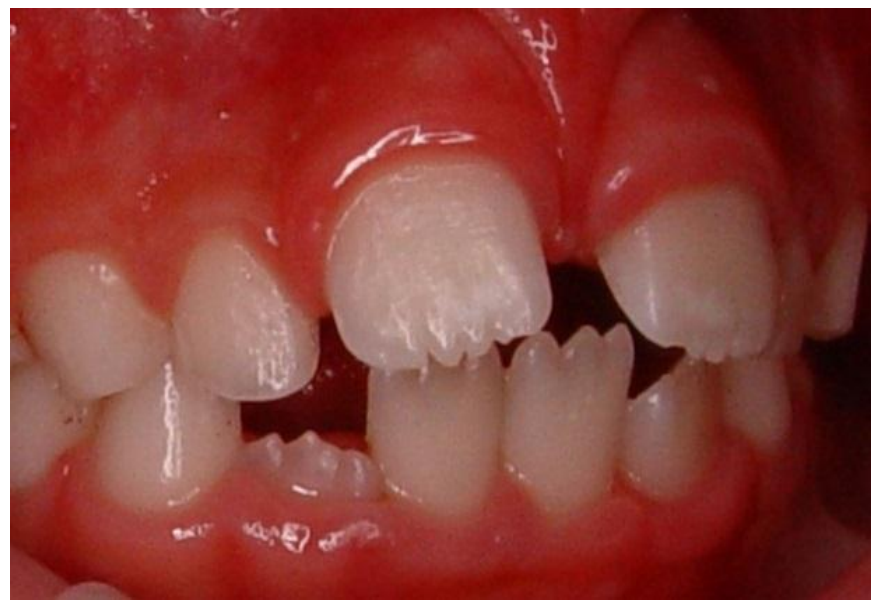

Resim 3.

Sürmesi tamamlanmış sağ üst daimi lateral dişin radyografik görüntüsü

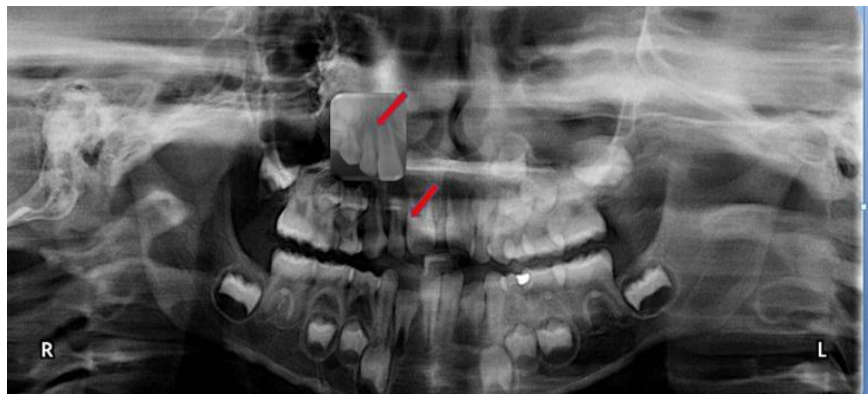

Resim 4.

Sürmesi tamamlanmış sağ üst daimi lateral dişin radyografik görüntüsü 


\section{OLGU 2}

Maksiller sağ süt kanin dişinin sürmemesi şikayeti ile kliniğimize başvuran hastanın $\left(9 ; \partial^{\lambda}\right)$ ebeveyninden alınan anamnez sonucunda herhangi bir sistemik rahatsızlığının bulunmadığı öğrenildi. Yapılan ağız içi muayenede sağ üst kanin haricindeki tüm süt dişlerinin ağızda ve normal pozisyonlarında oldukları, şikayet bölgesinde ise bukkale doğru yayılım gösteren bir şişliğin varlığı izlendi (Resim 5). Yakın zamanda herhangi bir travma veya enfeksiyon hikayesi bulunmayan hastanın radyolojik muayenesinde ilgili bölgede radyolusent bir follikül içerisine yerleşmiş çoklu radyoopak kitlelerin bulunduğu, bu oluşumun altında süt kanin dişin gömülü olarak kaldığı tespit edildi (Resim 6). Mevcut klinik ve radyografik muayene sonucunda odontoma ön tanısı ile hasta fakültemiz Ağız, Diş, Çene Hastalıkları ve Cerrahisi Anabilim Dalı'na yönlendirildi. Kitle, pedodontist eşliğinde eksize edildi, yapılan histopatolojik incelemenin sonucu ön tanımızı destekler nitelikte kompound odontoma tanısını doğruladı. Operasyon sonrasında yapılan rutin kontrollerde süt kanin dişin sürmeye başladığı gözlendi (Resim 7).

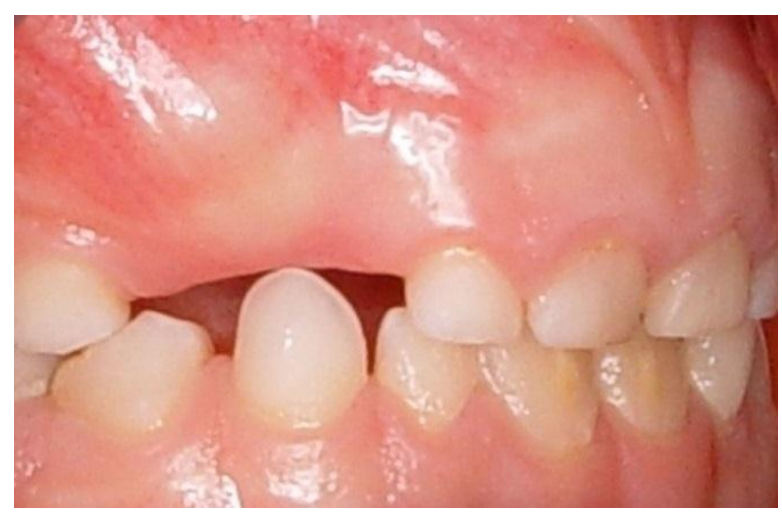

Resim 5.

Sağ üst sürmemiş kanin dişi bölgesinde belirgin şişlik

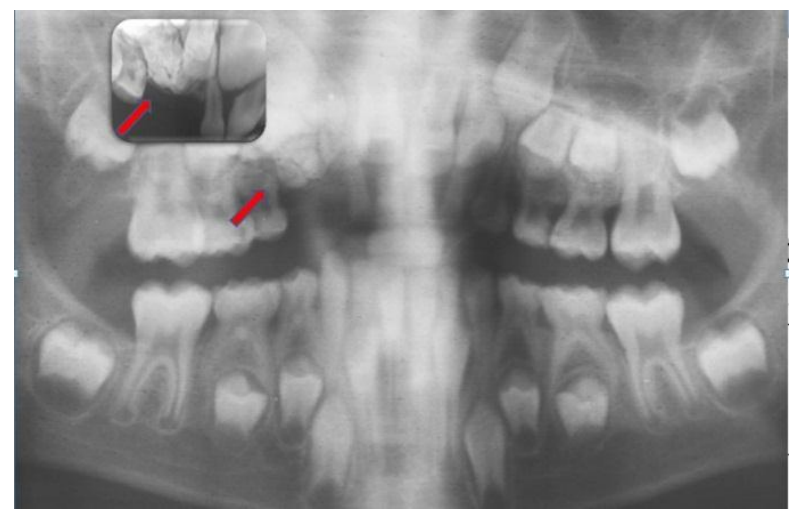

Resim 6.

Gömülü süt kanin ve çoklu radyoopak kitlenin görünümü

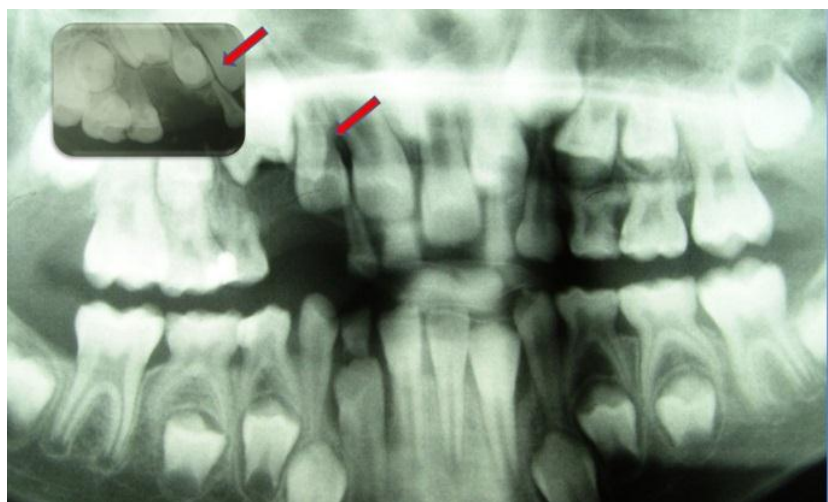

Resim 7.

Operasyondan 3 ay sonra alınan radyografi, süt kanin dişin sürme hareketinin bașlaması

\section{TARTIŞMA}

Dişlerin gömülü olarak kalması ve bu nedenle oluşan patolojiler diş hekimlerinin sıklıkla karşılaştığı problemlerdendir. Gömülü dişler sıklıkla daimi dentisyonda görülürken, nadir olarak süt dentisyonda da görülebilmektedir. Dişlerin gömük kalmasına neden olan birçok lokal etyolojik faktör tanımlanmıştır. Travma, ankiloz, dilaserasyon, malpozisyon, odontoma, diğer odontojenik tümörler, süpernumere dişler, süt dişinin erken kaybı nedeniyle skar dokusu oluşumu ve yer darlığı bu faktörlerin arasında yer almaktadır (Yildirim ve ark 2007, Batra ve ark 2004). Bu faktörler arasında, odontoma yaygın bir etyolojik faktör olarak ön plana çıkmaktadır (Teruhisa ve ark 2009). Bu vaka raporunda bahsi geçen ikinci olgu değerlendirildiğinde, literatürdeki bilgiler ile paralel şekilde anterior bölgede süt kanin dişinin gömülü olarak kalmasına neden olan kitle kompound odontoma olarak teşhis edilmiştir.

Odontomalar, dişlerin gömük kalmasına neden olabilmesinin yanı sıra, komşu dişlerde devitalizasyon, malformasyon, malpozisyon, dişin konjenital eksikliği gibi patolojilere de neden olmaktadır (Amailuk ve Grubor 2008, Karacay ve ark 2012, Hisatomi ve ark 2002). Bahsedilen ilk olguda, bu bilgiler ile uyumlu olarak, sağ süt lateral kesici dişin konjenital eksikliği, aynı bölgede odontoma varlığı ile birlikte tespit edilmiştir.

Odontomalar, genellikle yaşamın ilk ve ikinci dekatı içinde karşılaşılan ve gerçek tümörler yerine, gelişimsel anomaliler (hamartomlar) olarak kabul edilen oluşumlardır (Oliveira ve ark 2011, Batra ve ark 2009, Teruhisa ve ark 2009). Odontomaların etyolojisi tam olarak bilinmemektedir. Travma, enfeksiyon, ailesel hikaye ve genetik mutasyon sebebiyle 
gelişebileceği düşünülmektedir (Ferrer ve ark 2007). Odontomalar genellikle asemptomatiktir ve birçok zaman tanısı radyografik muayene esnasında konmaktadır. Kompound odontoma radyografide, küçük ve çok sayıda diş benzeri yapının lezyon içerisinde yer aldığı, etrafı radyolusent düzenli bir sınır ile çevrili, ortası radyoopak bir görüntü vermektedir (Bordini ve ark 2008). Klinik olarak ise genellikle maksiller kanin ve kesici dişler bölgesinde ağrısız bir şişlik şeklinde görülür (Bordini ve ark 2008, Karacay ve ark 2012). Burada bahsi geçen her iki vakada da literatür ile uyumlu klinik ve radyografik bulgular tespit edilmiştir.

Odontomaların tedavisi cerrahi eksizyondur. Kistik dejenerasyon potansiyeli nedeniyle odontomanın etrafındaki yumuşak doku ile birlikte eksizyonu önerilen tedavi şeklidir (Yeung ve ark 2003). Eksize edilen tüm odontomaların mikroskobik inceleme ve kesin tanı için patolojik incelemeden geçirilmesi gerekmektedir (Oliveira ve ark 2001, ArealLopez ve ark 1992). Bu vaka raporunda, her iki lezyon da cerrahi işlemin ardından histopatolojik incelemeye gönderilmiş ve ön tanımızı destekler nitelikte kompound odontoma teşhisi doğrulanmıştır.

Odontomaların cerrahi eksizyonunun ardından, dental arkta yer mevcutsa gömülü kalan dişlerin kendiliğinden sürme eğiliminde olduğu pek çok yazar tarafından bildirilmiştir (Yildirim ve ark 2007). Sürmenin gerçekleşmediği durumlarda veya ilk operasyon esnasında daha az tercih edilen bir yaklaşım ise sürmeyi kolaylaştırmak için cerrahinin ardından ortodontik olarak dişin sürdürülmesidir (Tomizawa ve ark 2005). Fakat bu yaklaşım zayıf bir gingival marjin, yetersiz dişeti bağlantı ataşmanı ve sürdürülen diş ile komşu dişler arasında dişeti seviyesinde farklılıklara neden olabilmektedir (Hattab ve ark 1994). Bu nedenle, her iki olguda da, dental arkta yer mevcudiyeti olması ve etkilenen dişlerin kendiliğinden sürme eğilimi nedeniyle yalnızca odontomanın cerrahi olarak çıarılması ve düzenli takibi tercih edilmiştir. Olguların takibinde, yapılan tedavinin olumlu sonuçlar verdiği, birinci olguda odontomanın oluştuğu bölgede yer alan daimi lateral dişin dental arkta yer aldığı, ikinci olguda ise gömülü kalan süt kanin dişin cerrahi operasyonun hemen ardından sürmeye başladığı gözlenmiştir.
Sonuç olarak, lezyonun erken yaşta tanı ve tedavisinin yapılması ile gelişmekte olan okluzyon üzerine herhangi bir zararlı etki oluşmaksızın tüm dişlerin normal pozisyonlarını almaları sağlanabilecektir. Bu sebeple karışık dişlenme döneminde yapılacak ayrıntılı dental muayenenin daimi dişlenmeye sağlıklı bir geçişin sağlanmasında büyük yararlar sağlayacağı düşünülmektedir.

\section{Süt dişleriyle ilişkili kompound odontoma: İki olgu}

Çenelerde görülen odontojenik kaynaklı tümörlerin \% 22 'sini oluşturan odontomalar, mine, dentin ve pulpa dokusu içeren hamartamatöz lezyonlardır. Odontomalar benign odontojenik tümörler olarak sınıflandırılmaktadır. Morfolojik olarak kompleks ve kompound odontoma olarak ikiye ayrılmaktadır. Kompound odontomalar yaygın olarak maksillada keser-kanin bölgesinde gelişmektedirler ve kompleks odontomalara göre iki kat daha fazla görülürler. Genellikle asemptomatiktirler ve rutin dental radyografi esnasında teşhis edilirler. Odontomalar diş sürme bozuklukları, komşu dişlerde konjenital eksiklik, rezorpsiyon ve malpozisyon gibi durumlarla ilişkilendirilmektedir ve sıklıkla daimi dentisyonda görülürken, nadir olarak süt dentisyonda da görülebilmektedir. Bu vaka raporunda; süt dişleriyle ilişkili iki kompound odontoma vakasının sunulması amaçlanmıştır..

ANAHTAR KELIMELER

Gömük diş, kompound odontoma, süt dişleri 


\section{KAYNAKLAR}

Amailuk P, Grubor D, 2008. Erupted compound odontoma: case report of a 15-year-old Sudanese boy with a history of traditional dental mutilation. $\mathrm{Br}$ Dent J, 204, 11-4.

Areal-López L, Silvestre DF, Gil LJ, 1992. Compound odontoma erupting in the mouth: 4 year follow-up of a clinical case. J Oral Pathol, 21, 285-8.

Batra P, Duggal R, Kharbanda OP, Parkash H, 2004. Orthodontic treatment of impacted anterior teeth due to odontomas: A report of two cases. J Clin Pediatr Dent, 28, 289-94.

Bordini J Jr, Contar CM, Sarot JR, Fernandes A, Machado MA, 2008. Multiple compound odontomas in the jaw: case report and analysis of the literature. J Oral Maxillofac Surg, 66, 2617-20.

Ferrer Ramirez M, Silvestre Donat F, Torres-Gomez F J, Avella-Vecino F, Salazar-Fernandez C, 2001. Recurrent infection of a complex odontoma following eruption in the mouth. Med Oral, 6, 269-75.

Gomez RS, Castro WH, Gomes CC, Loyola AM, 2013. Adenomatoid odontogenic tumor associated with odontoma: a case report and critical review of the literature. Head Face Med, 9, 20-26.

Hattab FN, Yassin OM, Rawashdeh MA, 1994. Supernumerary teeth: Report of three cases and review of the literature. J Dent Child, 41, 199-202.

Hisatomi M, Asaumi $\mathrm{Jl}$, Konouchi $\mathrm{H}$, Honda $\mathrm{Y}$, Wakasa T, Kishi K, 2002. A case of complex odontoma associated with an impacted lower deciduous second molar and analysis of the 107 odontomas. Oral Dis, 8, 100-5.

Karacay S, Gurbuzer B, Erkan M, Kucukodaci Z, 2012. Mandibular Canine Transmigration Associated with Compaund Odontoma: Case Report. Turkiye Klinikleri J Dental Sci, 18, 103-8

Kramar IRH, Pindporg JJ, Shear M. World health organization international histological classification of tumours -histological typing of odontogenic tumours. 2nd Ed. Springer-Verlag Berlin, P:11, 1992.

Lee CH, Park GJ (2008) Complex and compound odontomas are clinico-pathological entities. Basic Appl Pathol 2008;1:30-33
Neville BW, Damm DD, Allen CM, Bouquot JF, 2002. Odontogenic cysts and tumors. In: Oral and maxillofacial pathology. 2nd Ed. Denis P. Lynch. WB Saunders Co Philadelphia, p:631-2.

Oliveira BH, Campos V, Marcal S, 2001. Compound odontoma diagnosis and treatment: three case reports. Pediatr Dent, 23, 151-57.

Stajcic ZZ, 1998. Odontoma associated with a primary tooth. $J$ Pedodont, 12, 415-20.

Teruhisa U, Murakami J, Hisatomi M, Yanagi $\mathrm{Y}$, Asaumi J, 2009. A Case of Unerupted Lower Primary Second Molar Associated with Compound Odontoma. Open Dent J, 13, 173-6.

Tomizawa M, Otsuka Y, Noda T, 2005. Clinical observations of odontomas in Japanese children: 39 cases including one recurrent case. Int $J$ Paediatr Dent, 15,37-43

Yeung KH, Cheung RC, Tsang MM, 2003. Compound odontoma associated with an unerupted and dilacerated maxillary primary central incisor in a young patient. Int J Paediatr Dent, 13, 208-12.

Yildirim OZ, Tosun G, Kiziloglu G, Durmus D, Sener $Y, 2007$. An unusual association of odontomas with primary teeth. Eur J Dent, 1, 45-9.

\section{Yazışma Adresi:}

Yrd.Doç.Dr.Ebru Küçükyılmaz

İzmir Kâtip Çelebi Üniversitesi

Diş Hekimliği Fakültesi Pedodonti AD

Aydınlık Evler Mahallesi, Cemil Meriç Caddesi

6780 Sokak. No:48, 35640-Çiğli / IZMiR

Tel: +90 (232) 3254040

Fax: +90 (232) 3252535

E-mail: ebrukucukyilmaz@hotmail.com 